\title{
SINDROME DO APICE DA PIRAMMIDE (GRADENIGO) CONSEQÜENTE A TRAUMATISMO CRANIANO POR BALA
}

\author{
Roberto Mrearagno Filho* \\ Paulo Braga magalháeg **
}

A raridade com que um traumatismo por bala determina a síndrome de comprometimento associado dos $5 .^{\circ}$ e $6 .^{\circ}$ nervos cranianos do mesmo lado, desacompanhada de qualquer outro sinal de lesão do sistena nervoso, justifica o registro dêste caso.

Orservação - A. B., 21 anos, masculino, solteiro, branco, registro H. C. 186.877. Examinado em 25-5-1950. No dia 16 de dezembro de 1949, o paciente foi acidentalmente atingido por um tiro de espingarda, tendo a bala entrado pela parede externa da região orbitária esquerda e, dirigindo-se da esquerda para a direita, foi-se alojar na região temporal direita. O paciente não perdeu os sentidos; imediatamente percebeu a perda da vista esquerda. Já desde essa ocasião, notou sensação de adormecimento na hemiface direita e pouco tempo depois verificou que, para mastigar, era obrigado a usar o lado esquerdo, pois que os músculos masticatórios haviam perdido tôda sua fôrça. Jamais teve diplopia, mesmo porque a perda da vista esquerda fôra imediata. Em abril de 1950, começou a notar inflamaçẫo da conjuntiva direita, com supuração e gradual diminuiçăo da visão no ôlho direito, dando ao doente a sensação de nuvens sôbre a vista. Nada digno de mençăo apresentam seus antecedentes familiares e pessoais. Exame físico normal.

Examo neurológico -- Ligeira assimetria facial, com tendência a repuxamento dos traços fisionômicos para a esquerda. A contração dos platismas, nota-se maior relêvo dos mesmos à esquerda. A contração dos músculos orbiculares dos lábios é um pouco mais nítida do lado esquerdo da bóca com relação ao direito. $O$ ôlho direito apresenta-se em estrabismo convergente e sua córnea com os característicos descritos no exame ocular. O paciente evidencia integridade mental e o estudo da motricidade e da sensibilidade em suas diversas formas nada revela de anormal, exceção feita ao que concerne aos nervos cranianos. $O$ oblho esquerdo, enucleado, foi substituído por ôlho protético. Nervos trigêmeos - Normal à esquerda. A direita, anestesia táctil, térmica e dolorosa em todo o território de distribuição do nervo. Normal a sensibilidade superficial no pavilhão auditivo direito (integridade sensitiva da faixa de distribuição do nervo intermédio). O emprêgo de um tubo de ensaio com água em temperatura elevada (aproximadamente $70^{\circ} \mathrm{C}$ ) no estudo da sensibilidade no território do trigêmeo direito não provoca no paciente nenhuma sensação, nem mesmo em "picadas" (conforme foi descrito por Helson ${ }^{1}$ ). O reflexo corneano direito está totalmente abolido. Não há distúrbios tróficos aparentes na pele da hemiface direita em relação à esquerda; ausência de exagêro de secreçð̃es sebáceas ou

Trabalho apresentado ao Departamento de Neuro-Psiquiatria da Associação Paulista de Medicina, em 5 setembro 1950.

* Assistente de Clínica Neurológica da Fac. Med. da Univ. de São Paulo (Prof. A. Tolosa).

* Assistente de Clínica Oftalmológica da Fac. Med. da Univ. de São Paulo (Prof. Ciro de Resende). 
sudorais no lado anestesiado. A temperatura é sensìvelmente igual em lados simétricos da face, conforme tivernos a ocasião de verificar por medidas termoelétricas cutâneas. Igualmente, não há secreção maior na mucosa nasal direita em relação à esquerda. Sensibilidade profunda palestésica: normal e igual de ambos os lados, com diapasão de 128 duplas vibrações por segundo; nítida hipopalestesia no território do trigêmeo direito, ao diapasão de $256 \mathrm{dv} / \mathrm{s}$. Absoluta paralisia do componente motor do trigêmeo à direita. i abertura máxima da bôca, há nítido desvio da mandíbula para o lado paralisado; a linha entre os incisivos inferiores se desloca de cêrca de $2 \mathrm{~cm}$ para a direita da linha entre os incisivos superiores. $O$ movimento de didução da mandíbula para o lado são está prejudicado e sua excursão para êsse lado, muito limitada (paralisia do músculo pterigóideo externo). $\Lambda$ úvula não evidencia desvios, enquanto que o pilar posterior do veu, à direita, está nitiłlamente mais baixo que o do lado oposto (paralisia do músculo peristafilino externo). Ao cerrar fortemente os dentes, há nítida diminuição da energia contrátil dos músculos temporal e masseter direitos que, contudo, não exibem amiotrofias. Nervos faciais - Não há verdadeiras paralisias faciais, embora a inspeção sugira o aspecto de ligeira paresia facial direita (pseudoparalisia das anestesias trigeminais). Gustação nos dois terços anteriores da língua conservada. Nervos auditivos - Pars cochlearis: ligeira hipoacusia bilateral, mais pronunciada à direita e afetando principalmente os sons graves. Pars vestibularis sem alterações. Nervos bulbares normais.
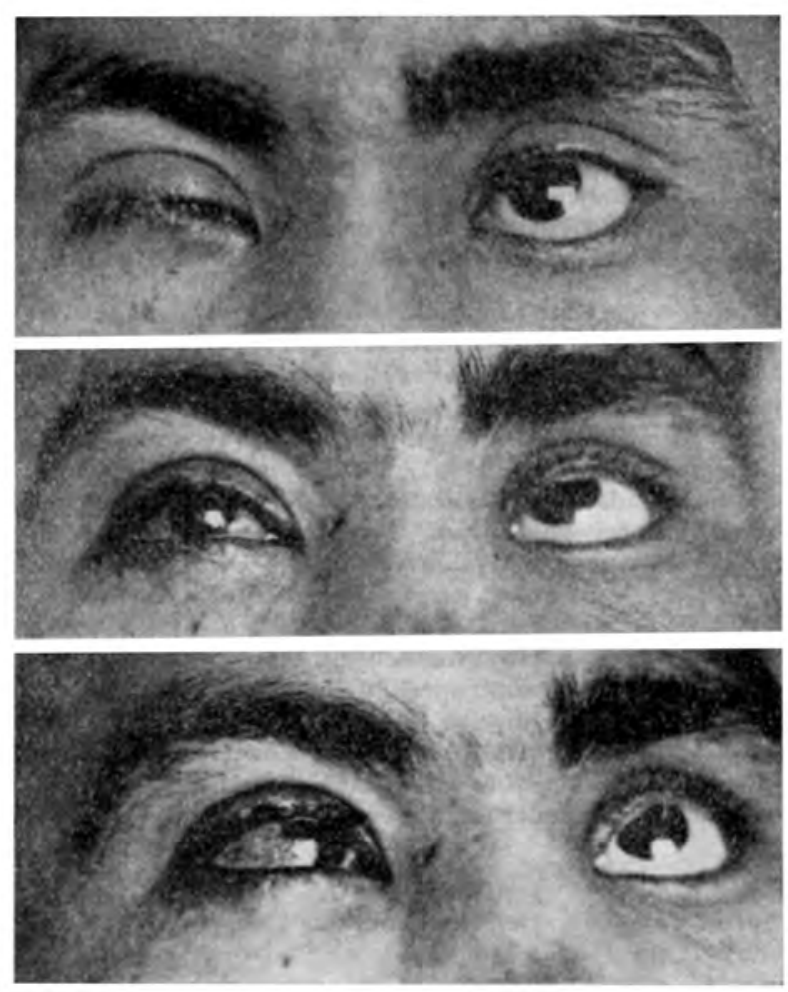

Fig. 1 - Caso A. B. Blefarorrafia devido a queratite paralítica; estrabismo no ôlho direito por paralisia do reto externo; ólho esquerdo protético. 

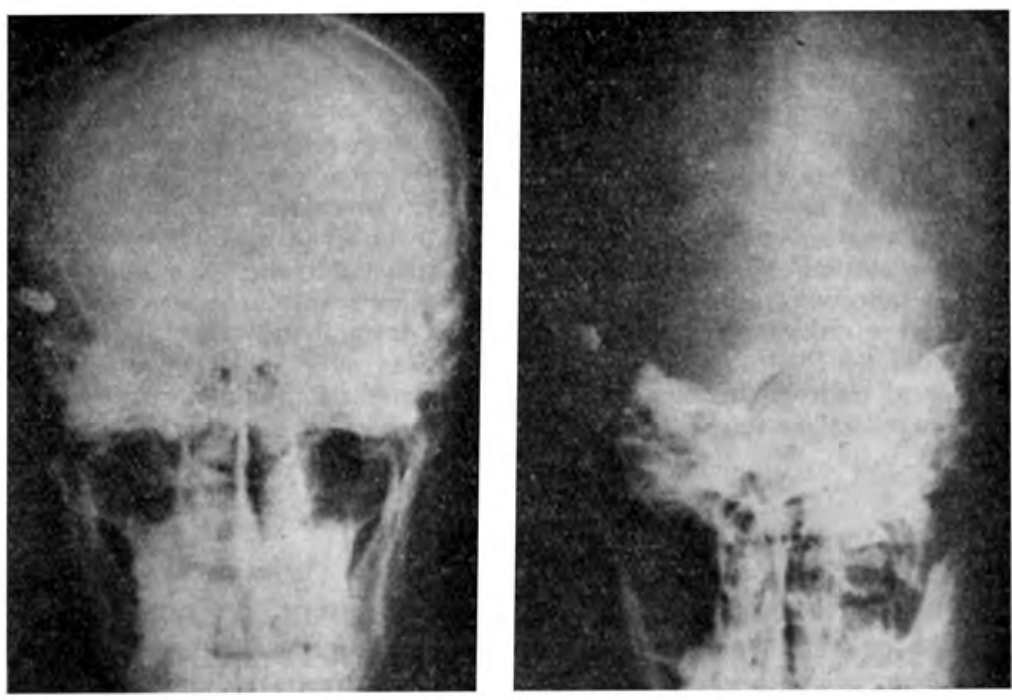

Fig. 2 - Caso A. B. Em A, radiografia em incidência de frente: ausência de fraturas; bala alojada na fossa temporal direita. Em $B$, radiografia em incidência de Towne: ausência de fratura do ápice da pirâmide.

Exame oftalmológico - Acuidade visual em OD, dedos a 2 metros; em OE, zero (prótese). Exame externo: Em OD, hiperemia das conjuntivas com opacificação da córnea no setor inferior. Em $\mathrm{OE}$, anoftalmo. Sensibilidades táctil e dolorosa da pele da hemifronte e hemiface direitas abolidas; sensibilidades corneana e conjuntival abolidas. Musculatura extrínseca: estrabismo paralítico convergente em OD (paralisia do abducente). Exame biomicroscópico: Em OD, congestão conjuntival e periquerática. Infiltração celular e vascularização superficial de tôda a metade inferior da córnea, onde se percebe uma depressão central. Exame oftalmoscópico: Em OD, papilas de limites, coloração e nível normais. Artérias e veias de calibre e curso normais. Assim, sob o ponto de vista oftalmológico, foi firmado o diagnóstico: em OD, estrabismo paralítico convergente, queratite neuroparalítica; em $\mathrm{OE}$, anoftalmo cirúrgico. A prova dos colírios, se bem que prejudicada pelo fato de só podermos observar as reações pupilares em um ôlho, nada revelou de anormal, pois as respostas pupilares de OD à adrenalina e cocaína, pilocarpina e eserina, homatropina e atropina foram precisas e constantes.

Radiografias do crânio - a) Frente e perfil: ausência de traços de fraturas; bala situada na região temporal direita e rastilho metálico na região orbitária esquerda e ao longo da fossa cerebral anterior (fig. 2). b) Posição de Vincent-Breton ('Towne) - Nota-se o rastilho metálico ao nível da superfície superior do rochedo direito. c) Posição de Stenvers - Ausência de sinais de fratura. d) Fundo de órbitas: à direita, buraco óptico e fenda esfenoidal de aspecto normal; à esquerda, fenda esfenoidal de aspecto normal. $O$ buraco óptico não parece estar alterado, porém, o rastilho metálico impede a boa visibilidade dos contornos. Exame de líquiido cefalorraquidiano, normal. O exame elétrico dos nesvos facial e trigêmeo revelou, em conclusão, inexcitabilidade farádica e galvânica no território do nervo trigêmeo direito. Prova de Minor - Sudorese em áreas simétricas. Reação de Kahn no sôro sangüineo, negativa. 
Evolução - O paciente foi internado na Clínica Oftalmológica do Hospital das Clínicas e nossos primeiros cuidados convergiram para o tratamento da queratite neuroparalítica, que tornava iminente a perda irreversível também da visão direita. Assim, foi feita blefarorrafia total de OU em 26-5-50, só tendo sido retirados os pontos em 2 6-6-1950, quando verificamos grandes melhorias no aspecto corneano. Datam de então as fotografias que ilustram êste registro (fig. 1). Em 30 de junho, a acuidade visual era, em $O D$ 0,4; em OE 0,0. Notava-se acentuada mácula corneana no lugar da depressão anterior e uma nébula no setor inferior da córnea. Fundo ocular normal. Desde a blefarorrafia, o paciente começou a acusar dôres não paroxísticas, sobretudo no território do nervo of tálmico direito; essas dóres não eram muito intensas e cederam durante a evolução do tratamento. Finalmente, o paciente foi revisto em 4-9-1950: visũo em OD 0,8; não se nota mais que uma nébula corneana no local onde se instalou a queratite neuroparalítica $e$ o estrabismo convergente por paralisia do reto externo.

\section{COMENTARIOS}

0 diagnóstico topográfico da lesão não oferece, em nosso caso, maiores dificuldades. A hala, após haver lesado indelèvelmente o globo ocular esquerdo, tomou a direção da esquerda para a direita e da frente para trás, indo finalmente se alojar na região temporal direita. O projétil, como se pode verificar pela poeira metálica visível nas radiografias de frente e na incidência de Vincent-Breton, passou tangencialmente pela superfície superior da pirâmide direita, na altura de seu ápice. Compreende-se então o comprometimento associado do gânglio semilunar de Gasser com a raiz motora do trigêmeo e do nervo abducente, configurando uma síndrome descrita por Gradenigo em certos casos de meningites localizadas na ponta do rochedo, resultantes de infecções das células mastöideas (Grinker ${ }^{1}$ ) ou, algumas vêzes, de tromboflebites do seio petroso inferior (Symonds ${ }^{2}$ ). Como na quase totalidade dos casos, a síndrome do comprometimento associado do ahducente e do trigêmeo (êste em intensidade variável) é devida à propagação para o ápice da pirâmide de infeç̧ões de vizinhança, a síndrome de Gradenigo vem sempre estudada no capítulo das moléstias infecciosas do sistema nervoso. Segundo Wechsler ${ }^{3}$, além da petrosite, uma eventual osteomielite da ponta do rochedo pode ser a causa etiológica da síndrome. Outras vêzes (Walshe ${ }^{4}$ ), o comprometimento associado dos nervos trigêmeo e abducente depende de abscessos extradurais; nesses casos, a infecção progride ao longo do osso petroso, com conseqüente edema do ligamento temporosfenoidal e compressão do $6 .^{\circ}$ nervo craniano subjacente.

$\mathrm{Na}$ literatura que compulsamos, não encontramos referências a casos semelhantes ao nosso, no qual a lesão completa dos $5 .^{\circ}$ e $6 .^{\circ}$ nervos cranianos dependesse de traumatismo por bala. A raridade dessa etiologia é fàcilmente compreensível pelo fato da elevadíssima mortalidade das feridas penetrantes do andar médio do crânio, em razão, principalmente, das lesões dos grandes vasos adjacentes (Rowbotham ${ }^{5}$ ). Realmente, nos traumatismos agudos do crânio, o comprometimento dos nervos oculomotores pode-se processar, quer por fraturas da órbita, quer por estiramento dos nervos na fossa posterior, quando o encéfalo é deslocado no momento do choque. 0 nervo 
trigêmeo, na maior parte das vêzes, apenas é atingido nas porções mais periféricas, o que se traduz por áreas de anestesia local. 0 gânglio de Casser pode ser afetado por fraturas basais que cruzam a ponta da pirâmide. Devemos assinalar ausência de qualquer fratura, no caso que registramos.

Infelizmente, o lapso de tempo relativamente longo de 5 meses, entre o traumatismo e nosso primeiro exame, prejudicou diversas provas relativas ao sistema nervoso simpático, sobretudo ao simpático ocular. Por outro lado, a perda do ôlho esquerdo, substituído por prótese, ainda mais dificultou as provas dos colírios, devido à impossibilidade de um critério comparativo entre os dois lados.

Merece realce, em nosso caso, a magnífica regressão da queratite neuroparalítica apenas pela blefarorrafia do ôlho afetado. Reproduziram-se, assim, em nosso paciente, as elegantes experiências de Snellen ${ }^{6}$ (1857) quando, para comprovar sua teoria traumática da queratite neuroparalítica, mostrou que a sutura da orelha do coelho diante das pálpebras anestesiadas, evitava qualquer infecção corneana. A tendência moderna para explicar a gênese da queratite paralítica é eclética: ao que parece, nas lesōes do trigêmeo, colaboram na infecção corneana, ao lado dos microtraumatismos sôbre o globo ocular e pálpebras anestesiados, distúrbios tróficos e um dissecamento da superfície corneana $\left(\operatorname{Garcin}{ }^{7}\right)$.

Em nosso paciente, observava-se, à inspecção, certa assimetria facial, dando a impressão de leve paresia periférica do nervo facial direito. No entanto, a energia de contração dos músculos mímicos pràticamente era tão intensa de um lado quanto de outro. Esse fenômeno já havia sido produzido experimentalmente por Charles Bell e observado no homem por Cushing ${ }^{8}$, após neurectomias do trigêmeo.

Finalmente, outro aspecto interessante de nosso caso se refere ao com. portamento da sensibilidade profunda vibratória no lado afetado: enquanto que o paciente acusava idêntica sensação em ambos os lados, to diapasão de 128 duplas vibrações por segundo, apresentava nítida hipopalestesia, no lado comprometido, ao diapasão de 256 vibrações. Como é sabido, discordam os neurofisiologistas quanto à via de condução da sensibilidade profunda da face. Para alguns seria veiculada pelo nervo intermédio de Wrisberg, enquanto que, para outros, trafegaria pelo próprio nervo trigêmeo.

\section{RESUMO}

Registro de um caso de traumatismo craniano por bala de espingarda. O exame realizado cinco meses após o acidente revelou perda completa da vista esquerda, intensa queratite neuroparalítica no ôlho direito, que apresentava estrabismo convergente e comprometimento completo, molor e sensitivo, do nervo trigêmeo direito. As radiografias nas diversas incidências não demonstraram qualquer traço de fratura e a poeira metálica evidenciava uma lesão tangencial sôbre a superfície do ápice da pirâmide. $O$ globo ocular esquerdo foi enucleado e substituído por ôlho protético. À direita, 
foi feita blefarorrafia, a fim de melhorar as condições corneanas; realmente, houve regressão pràticamente completa da queratite. Estudam os auto res as diversas causas etiológicas da síndrome do ápice da pirâmide e realçam a raridade da etiologia traumática. Finalmente, consideram diversos aspectos clínicos do caso.

\section{SUMMARY}

The authors report a case of head injury by a bullet of a Winchester, caliber 22. The examination, made five months later, showed blindness of the left eye and severe neuroparalytic keratitis in the right eye which presented also a convergent strabism and a complete involvement (motor and sensitive) of the right trigeminal nerve. A detailed X-rays examination failed to reveal any fracture and the metallic dust showed a tangential lesion over the tip of the pyramid surface. The left eye was enucleated and replaced by a protectic eye. A blefarorraphy was done in the right side in order to improve the corneal conditions. Indeed, there was an almost complete regression of the keratitis. The authors study the several etiologic causes of the tip of the pyramid syndrome and emphasize the rarity of traumatic etiology. Finally, they comment the different clinical aspects of this case.

\section{BIBLIOGRAFIA}

1. Helson, H. - The part played by the sympathic system afferent mechanism in the region of the trigeminus. Brain, 1:114, 1932.

2. Grinker, R. R. - Neurology, ed. 3. Ch. C. Thomas, Springfield, 1943.

3. Wechsler, I. - A Textbook of Clinical Neurology. Saunders, New York, 1947.

4. Walshe, F. M. R. - Diseases of the Nervous System. E. \& S. I Livingstone, 1940.

5. Rowbotham, G. F. - Acute Injuries of the Head. Their diagnosis, treatment, complications and sequels. E. \& S. Livingstone, 1949.

6. Cit. por Garcin e Raymond ?.

7. Garcin, R. e Raymond - In Traité de Physiologie Normale et Pathologique, de Roger e Binet, Tomo 10. Physiologie Nerveuse (parte 2) Masson et Cie., Paris, 1935.

8. Cit. por Garcin e Raymond 6 .

Clínica Neurológica da Fac. Med. da Univ. de São Paulo. 